DOI: $10.14451 / 2.122 .106$

\title{
СОВРЕМЕННЫЕ АСПЕКТЫ ИННОВАЦИОННОЙ ДЕЯТЕЛЬНОСТИ СФЕРЫ МЕДИЦИНСКИХ УСЛУГ
}

\author{
(c) 2018 Борисова Анна Константиновна \\ аспирант кафедры предпринимательства и логистики \\ Российский экономический университет имени Г.В. Плеханова \\ 117997, г. Москва, Стремянный пер., 36 \\ E-mail: ak.borisova@mail.ru
}

Необходимость и целесообразность инновационного развития сферы медицинских услуг признается как в научных исследованиях, так и на законодательном уровне. Но опыт внедрения и развития инноваций как в отрасли здравоохранения, так в целом и в стране пока не дал должного результата, при этом в мировом масштабе некоторые позиции, характеризующие уровень развития, вовсе ухудшились. На основе анализа тенденций и факторов инновационного развития сферы медицинских услуг, а также сущности инновационной компоненты развития сферы медицинских услуг на настоящем этапе социально-экономического развития считаем целесообразным оперативное принятие решений по оптимизации механизмов инновационного развития сферы медицинских услуг как одного из звеньев общего инновационного и экономического развития.

Ключевые слова: инновации, инновационное развитие, сфера медицинских услуг, критерии инноваций, медицинская эффективность, социальная эффективность, экономическая эффективность.

Сфера медицинских услуг является важной отраслью развития любого государства, экономическому и инновационному аспекту развития которой в настоящее время уделяется активное внимание. Именно от постоянной корректировки стратегического и тактического поведения на основании актуальных показателей развития государства в целом и отрасли в частности с учетом изменяющихся социально-экономических условий во многом зависит успех развития отрасли.

Сегодня сфера медицинских услуг, несмотря на активное стремление научного и политического сообщества улучшить ряд особо важных показателей, имеет значительные трудности. Так, на основании данных Всемирной организации здравоохранения (ВО3), Организации Объединенных Наций $(\mathrm{OOH})$ и Всемирного банка, агентством Bloomberg составлен рейтинг стран мира по эффективности систем здравоохранения. В основе рейтинга взяты три основных показателя, которые и определяют эффективность системы здравоохранения той или иной страны: средняя ожидаемая продолжительность жизни при рождении, государственные затраты на здравоохранение в виде процента от ВВП на душу населения, стоимость медицинских услуг в пересчете на душу населения [7].

Согласно рейтингу стран мира по эффективности систем здравоохранения Россия в 2016 г. заняла 55 место, в то время как в 2014 г. в данном рейтинге Россия была указана на 51 позиции, что говорит об ухудшении уровня здравоохранения в России и одновременно о низком уровне эффективности системы (рисунке 1).

Английский философ и математик Альфред Уайтхед сказал: «У человечества есть только два пути: или развитие, или деградация». И только через внедрение и развитие инноваций возможно обеспечить поступательное движение развития общества.

Во всем мире производится оценка и ранжирование стран по уровню инновационного развития с помощью различных методик оценки. Следует отметить, что позиция Российской Федерации среди превалирующего количества таких рейтингов остается достаточно невысокой, при этом по некоторым из них даже ухудшилась в последнее время [2, 4].

На основании международного доклада «Тhe Global Innovation Index 2016. Winning with Global Innovation» Россия поднялась на 6 позиций в 2016 г. по сравнению с 2014 г. и находится на 43 месте в рейтинге стран по глобальному индексу инноваций (ГИИ) [8].

Итоговый рейтинг рассчитан как среднее двух субиндексов - ресурсов инноваций (предполагает существующие ресурсы для инноваций и условия для инновационного развития) и результатов инноваций (предполагает достигну- 


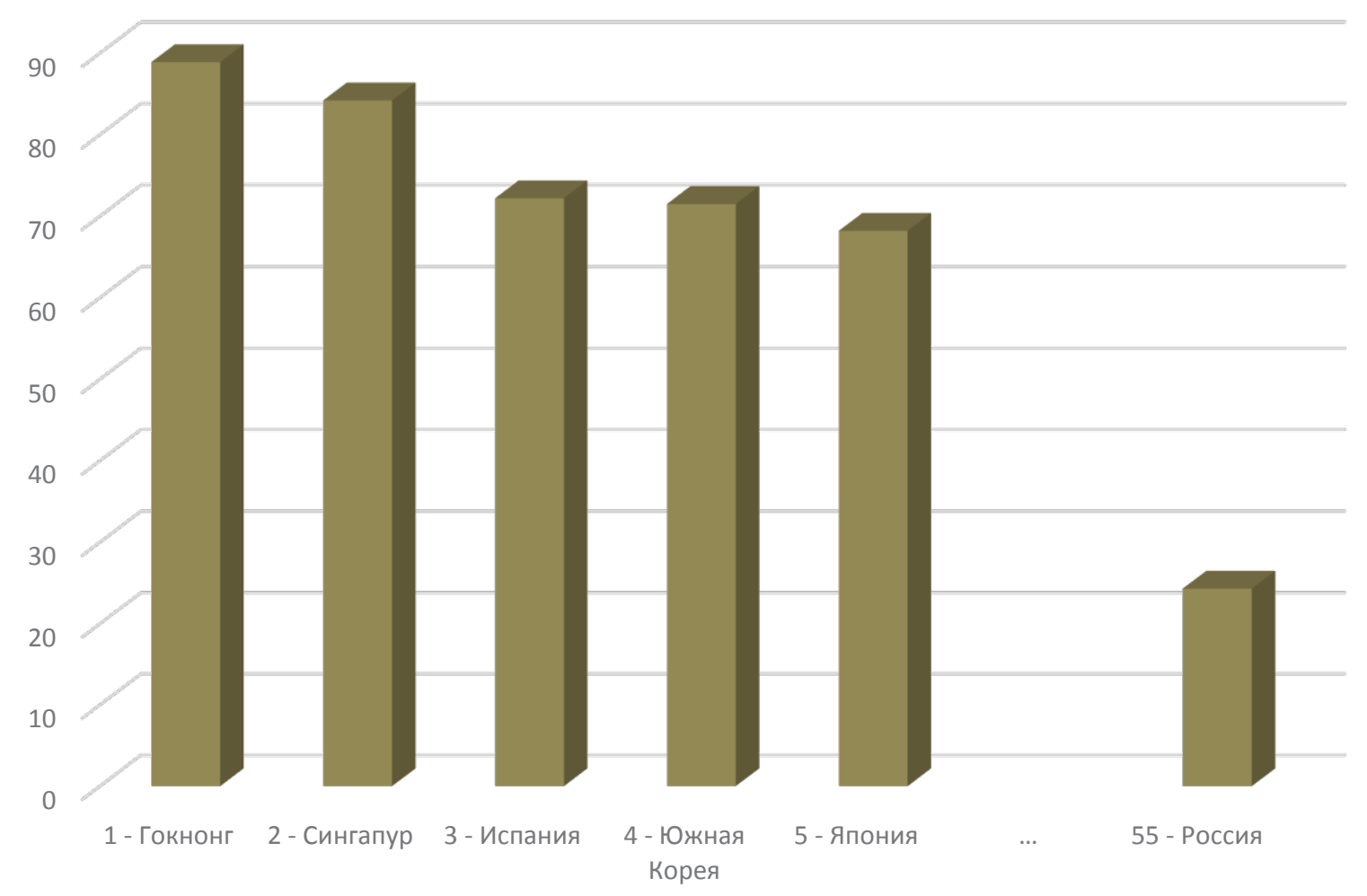

Puc. 1. Рейтинг стран по эффективности системы здравоохранения Диаграмма составлена на основании данных сайта www.bloomberg.com

тые практические результаты).

Данные глобального индекса инноваций в 2016 году показывают, что Россия значительно улучшила свои позиции по субиндексу ресурсов инноваций (44 место в 2016 г. по сравнению с 56 местом в 2014 г.), при этом по эффективности инновационной деятельности позиции России стали значительно слабее, что отражает перемещение России с 49 места на 69 в 2016 г. по сравнению с 2014 г. Это, по оценке авторов исследования, отражает недостаточно эффективную реализацию имеющегося инновационного потенциала (рисунке 2).

Особо следует подчеркнуть, что на законодательном уровне инновационный путь развития экономики России закреплен в Стратегии инновационного развития Российской Федерации на период до 2020 года, утвержденной в 2008 году. Необходимо подчеркнуть, что за планируемый период времени не удалось достигнуть желаемых результатов, а в ряде случаев эффективность сферы медицинских услуг сократилась вовсе.

Поэтому считаем особо важным на данном этапе совершенствование организационно-экономических механизмов инновационного развития сферы медицинских услуг и принятие оперативных решений по развитию сферы ме- дицинских услуг с учетом макроэкономических условий и тенденций глобального мирового кризиса посредством выявления и анализа основных факторов и тенденций данной отрасли.

Сегодня мировая экономика претерпевает значительные кризисные изменения. При этом интересен тот факт, что конъюнктурные волны, а в частности экономический рост, активно связаны с инновациями, что позволяет определить, что в настоящих социально-экономических условиях успех развития сферы медицинских услуг будет во многом зависеть от принятых решений в разрезе инновационного развития.

Следует отметить, что теоретическим и практическим вопросам инновационного развития посвящено большое число трудов российских и зарубежных исследователей. Вводя в научный оборот понятие инновации и давая его характеристику, Й. Шумпетер, являющийся первооткрывателем в данной области научного знания, в своем труде «Теория экономического развития» выделил ставшие уже классическими «пять типичных изменений» [6]:

1. Внедрение нового продукта, с которым потребитель еще не знаком, либо нового уровня качества существующей продукции.

2. Внедрение новых методов производства, которые либо основываются на научных откры- 


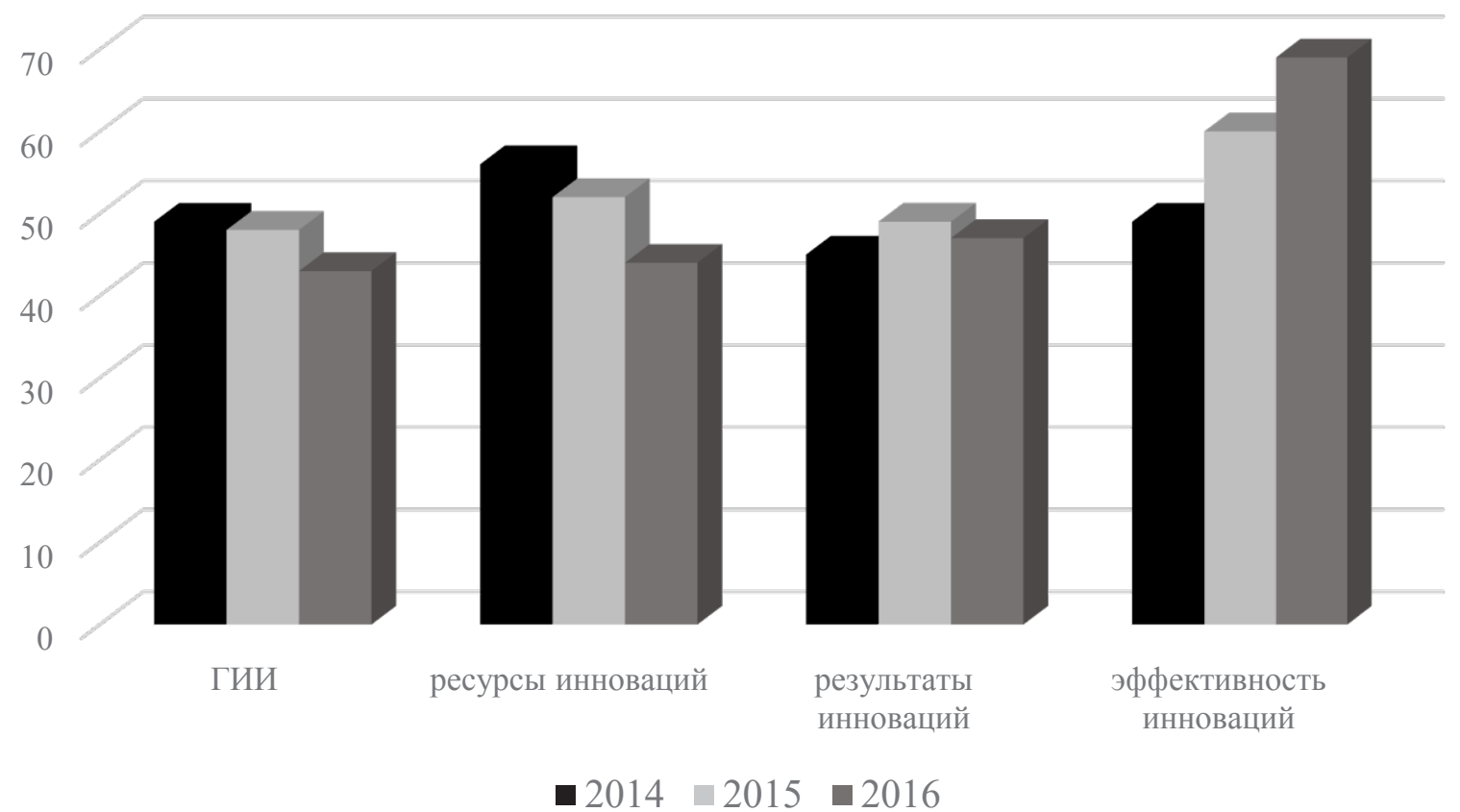

Puc. 2. Рейтинг России по глобальному индексу инноваций Диаграмма составлена на основании данных сайта http://innovation.gov.ru

тиях, либо могут представлять собой новый способ коммерческого использования продукта или сырья.

3. Открытие нового рынка, на который еще не заходила определенная отрасль производства некоторой страны, вне зависимости от того, существовал этот рынок раньше или нет.

4. Захват нового источника сырья или полуфабрикатов, опять же вне зависимости от того, существует ли данный источник, либо он только что был создан.

5. Реализация изменений в организации некой отрасли, в частности, занятие монопольной позиции (например, через создание трастов), или же его утеря.

Далее представления, классификация и основные особенности и принципы инноваций трансформировались. В настоящее время в научной литературе нет единого подхода к определению инноваций.

Законодательно инновации определены как «введенный в употребление новый или значительно улучшенный продукт (товар, услуга) или процесс, новый метод продаж или новый организационный метод в деловой практике, организации рабочих мест или во внешних связях» [1]. На наш взгляд, вышеуказанная трактовка является не полной и не отражает всей сути основных аспектов инноваций, поскольку важной составляющей инноваций и инновационного развития является эффективность их внедрения в настоящих условиях.

Таким образом, наиболее интересным, по нашему мнению, является следующее определение: «инновация (нововведение) - результат инновационной деятельности, получивший воплощение в виде нового или усовершенствованного продукта, внедренного на рынке, нового или усовершенствованного технологического процесса, используемого в практической деятельности, либо новой или усовершенствованной организационно-экономической формы, обеспечивающей необходимую экономическую и/или общественную выгоду» [3].

Рассматривая инновационное развитие сферы медицинских услуг, важным фактором в силу определённой специфики медицинской отрасли является многокомпонентная эффективность, которая включает медицинскую, социальную и экономическую эффективности [5].

Таким образом, полагаем, что, чтобы стать инновацией в сфере медицинских услуг, идея должна отвечать критериям новизны, медицинской, социальной и экономической эффективности, целесообразности и адаптивности в настоящих условиях хозяйствования. И только, отвечая всем вышеперечисленным критериям инновация может быть успешно внедрена и развита в сфере медицинских услуг.

Для целей настоящего исследования определим классификацию инноваций в сфере медицинских услуг, что во многом поможет система- 
тизировать подход к инновационному развитию сферы медицинских услуг.

Нами разработана и предложена следующая классификация инноваций в сфере медицинских услуг, основанная как на существующих, так и на новых, предложенных автором, признаках:

1. По области применения инновации различают:

- продуктовые (новые медицинские услуги),

- технологические (новые методы, способы

и средства профилактики, диагностики, лечения, реабилитации),

- организационно-управленческие (направленные на совершенствование методов организации труда, управления бизнес-процессами),

- экономические (направленные на улучшение основных экономических показателей),

- маркетинговые (направленные на применение маркетинговых инструментов реализации медицинских услуг),

- социальные (направленные на повышения качества и доступности медицинских услуг),

- информационные (направленные на автоматизацию основной информации, необходимой для оказания медицинских услуг).

2. По степени новизны и инновационному потенциалу выделяют инновации:

- радикальные (прорывные инновации, принципиально новые для существующей сферы медицинских услуг, меняющие привычный уклад хозяйствования),

- революционные (не столь масштабные как радикальные, но имеющие определенный эффект),

- нейтральные.

3. По роли в лечебно-диагностическом процессе определяют:

- медицинские инновации (новые медицинские услуги),

- обеспечивающие инновации (инновации, направленные на обеспечение оказания существующих видов медицинских услуг).

4. Сфера распространения - инновации, реализуемые в масштабах:

- государства,

- региона,

- учреждения.

5. По виду достижения эффективности инновации, нацеленные на увеличение:

- медицинской эффективности,
- социальной эффективности,

- экономической эффективности,

- интегральные.

6. По сроку существования:

- до 5 лет,

- 5-10 лет,

- 10-20 лет,

- Более 20 лет.

7. По отношению общества инновации с:

- позитивным отношением,

- негативным отношением,

- нейтральным отношением.

8. В зависимости от источника инновации, инициированные:

- потребителем,

- государством,

- медицинским учреждением,

- страховой компанией.

В настоящих условиях мирового глобального кризиса и реалий низкого уровня развития экономики России считаем наиболее целесообразным оптимизацию инноваций согласно вышепредложенной классификации и разработку алгоритма организационно-управленческого механизма обеспечения инновационного развития сферы медицинских услуг.

Определим, что среди основных факторов, препятствующих инновационному развитию сферы медицинских услуг можно выделить: низкий уровень развития отрасли, несовершенство нормативно-законодательной базы, недостаточность финансирования и низкий уровень заинтересованности в появлении, внедрении и продвижении инноваций как у поставщиков, так и у потребителей медицинских услуг, которые определили основные перспективные направления совершенствования инновационного развития сферы услуг:

- совершенствование нормативной и законодательной базы;

- разработка адаптивного механизма инновационного процесса с разграничением субъектов и их зон ответственности, алгоритмов и методов определения эффективности и целесообразности инноваций;

- создание условий для развития отрасли на конкурентной основе

- повышения квалификации медицинских и управленческих кадров, создание эффективной системы мотивации;

- формирование мотивации граждан на ведение здорового образа жизни и своевременной 
профилактики.

В силу высокой социальной значимости необходимо активное участие государства в инновационных процессах развития сферы услуг на макроуровне, мезоуровне и микроуровне, и только во взаимодействии которых возможно значительное качественное и количественное улучшение основных показателей развития сферы медицинских услуг.

При этом в настоящих социально-экономических условиях развития необходим курс не на радикальные (прорывные) инновации согласно предложенной автором классификации, которые успешно реализуются только в условиях развитой инновационной среды, а на формирование той самой необходимой инновационной среды посредством революционных продуктовых, технологических, организационно-управленческих и других, не столь масштабных как радикальные, но имеющие определенный эффект, направленный на поступательной развитие сферы медицинских услуг.

Таким образом, в настоящих социально-экономических условиях развитие сферы медицинских услуг должно происходить на основе комплексного устойчивого инновационного развития отрасли, которое невозможно без построения концептуальной модели оценки и механизмов внедрения инноваций, ее реализации в виде практического инструментария и одновременного управления и социальными, и организационно-экономическими процессами ее эффективности одновременно создавая устойчивую инновационную среду, которая послужит фундаментом дальнейшего инновационного развития, как отрасли здравоохранения в частности, так и государства в целом.

\section{Библиографический список}

1. Федеральный закон «О внесении изменений в Федеральный закон «О науке и государственной научно-технической политике» N254-Ф3 от 21 июля 2011 года. [Электронный ресурс]: http://www.consultant.ru/ document/cons_doc_LAW_117193/.

2. Архипова М.Ю, Лебедев А.В. Инновации и уровень жизни населения: взаимосвязь, тенденции, перспективы//Статистика и экономика. 2012. С. 91-95.

3. Винокуров В.И. Основные термины и определения в сфере инноваций / В.И. Винокуров // Инновации. 2005. № 4. С. 6-21.

4. Рожкова Е.В. Проблематика инновационно-ориентированного развития сферы здравоохранения//Социальные аспекты здоровья населения. 2014. Том 36, № 2 [Электронный ресурс]: http://vestnik.mednet.ru/.

5. Экономика здравоохранения. Учебное пособие для студентов педиатрического, лечебного и стоматологического факультетов. Санкт-Петербург. 2015. 72 с.

6. Шумпетер Й. Теория экономического развития. Капитализм, социализм и демократия / предисл. В.С. Автономова. [Текст]. Москва. 2007. 864 с.

7. Официальный сайт агентства Bloomberg [Электронный ресурс]: https://www.bloomberg.com/topics/healthcare.

8. Доклад «The Global Innovation Index 2016. Winning with Global Innovation» [Электронный ресурс]: http://innovation.gov.ru/ru/node/75123. 